\title{
Assessment of shear capacity. Part II: Experimental test
}

\author{
Maria Włodarczyk ${ }^{1, *}$ \\ ${ }^{1}$ Warsaw University of Technology, ul. L. Kaczyńskiego 16, 00-637 Warszawa, Poland
}

\begin{abstract}
Results of experiments carried out on beams with varying shear reinforcement are presented. Depending on the amount of transverse reinforcement different failure modes with different ultimate loads were recorded. The results were compared to theoretical load capacity estimates. Three models for shear capacity were used: classical, EC and Zararis described in the accompanying paper [1]. When shear failure mode governs beam behaviour, theoretical results according to the EC and Zararis are in good compatibility with experiments.
\end{abstract}

\section{Introduction}

Estimation of shear capacity of RC beams is a non-trivial problem, which cannot be described by simple analytical formulae [2-9]. It has to be mentioned, that beam design process for shear is more complex than design for bending. As a result, the problem of shear in RC elements is still the subject of an intense experimental research [3-8, 10-13], and new computational models are proposed. Interrelation between concrete, longitudinal and transversal reinforcement leads to inhomogeneity in stress distribution inside of the regarded element. Moreover, opening and propagation of inclined cracks, even in homogeneous material implies high internal forces redistribution and anisotropy of material due to cracking. Therefore, the problem has not been completely solved yet, numerous research is still conducted and new analytical models are formulated and experimentally validated.

This part of paper concerns performed experimental tests of four series of RC beams, with variable shear reinforcement ratio. Obtained results are compared with predictions of computational models presented in the part I. [1].

\section{Experimental test}

The carried out tests were done on four series of RC beams with cross-section dimensions: $80 \times 140 \mathrm{~mm}$ and span length of $1000 \mathrm{~mm}$. Each of series consisted of two beams with specified shear reinforcement ratio, changing from $0 \%$ to $1.4 \%$ for different series. A simply supported single-span beam as a static scheme was assumed. Two forces were

* Corresponding author: maria.wlodarczyk@il.pw.edu.pl 
applied in the distance of $a=300 \mathrm{~mm}$ from each support. Figure 1 shows the set-up and cross-section of the regarded beam.

a)

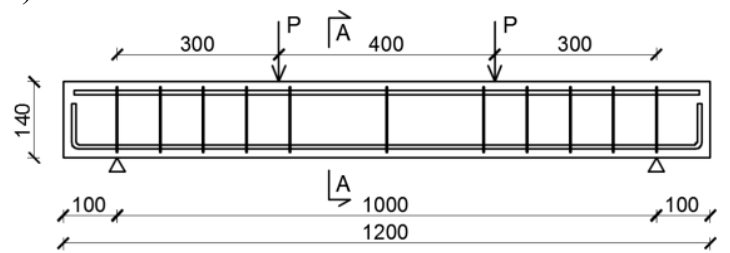

b)

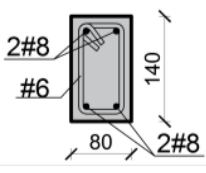

Fig. 1. a) Static scheme and reinforcement layout. b) Cross-section of beam.

Testing was performed on four series of RC beams, each consisted of two identical beams. The same steel and concrete class were used for all casted elements. Both longitudinal and transversal reinforcement were made of BSt500 steel, of diameter $\phi 8$ in case of longitudinal bars and of $\phi 6$ the stirrups. Each series varied in spacing and number of stirrups used.

In case of beams of the series number 1 only two stirrups over the supports were used, just only to hold longitudinal bars. Then shear reinforcement ratio is $\rho_{w}=0 \%$. Series number 2 contained stirrups over the supports and at the points of force application $\left(\rho_{w}=0.23 \%\right)$. Series number 3 contained stirrups of minimum transversal reinforcement $\left(\rho_{w}=0.78 \%\right)$ required by Eurocode 2 with maximum spacing of $s_{l, \max }=90 \mathrm{~mm}$. In series number 4 , higher shear reinforcement ratio was used $\rho_{w}=1.4 \%$.

Tests were conducted with a testing press able to apply load of $200 \mathrm{kN}$. Load was transferred to the beam by a crossbar, which could give maximum load of $P=100 \mathrm{kN}$ on each side of the beam.

Load was applied with steps of $1 \mathrm{kN}$ from $0 \mathrm{kN}$ to the sample failure. Each step was monitored by the Aramis (optical deformation measuring system), and at the selected steps by a strain gauge as well (i.e. for $0 ; 2.5 ; 5.0 ; 7.5 ; 10.0 ; 12.5 ; 15.0 ; 17.5 ; 20.0 ; 25.0$ and further by each $5 \mathrm{kN}$ to beam failure) $[14,15]$. Moreover, crack locations and accompanying widths, beam maximum deflection and the failure mechanism were monitored. Special attention was given to the zones near supports where shear failure was suspected $[14,15]$.

\section{Experimental results and its interpretation}

\subsection{Test of materials}

Tests for compressive strength and elastic modulus of concrete samples, were performed according to ITB [16] instruction. Obtained results are presented in Table 1.

Table 1. Concrete samples test results.

\begin{tabular}{|c|c|c|c|c|}
\hline $\begin{array}{c}\text { Series of } \\
\text { beams }\end{array}$ & $\begin{array}{c}\text { Beam } \\
\text { symbol }\end{array}$ & $\boldsymbol{f}_{\boldsymbol{c m}}[\mathbf{M P a}]$ & $\boldsymbol{f}_{\boldsymbol{c t m}}$ [MPa] & $\boldsymbol{E}_{\boldsymbol{c m}}[\mathbf{G P a}]$ \\
\hline \multirow{2}{*}{$\mathrm{I}$} & $\mathrm{B} 1-1$ & 32.58 & 3.06 & 31.35 \\
\cline { 2 - 5 } & $\mathrm{B} 1-2$ & 35.44 & 3.24 & 32.16 \\
\hline \multirow{2}{*}{ II } & $\mathrm{B} 2-1$ & 32.58 & 3.06 & 31.35 \\
\cline { 2 - 5 } & $\mathrm{B} 2-2$ & 35.44 & 3.24 & 32.16 \\
\hline \multirow{2}{*}{ III } & $\mathrm{B} 3-1$ & 32.58 & 3.06 & 31.35 \\
\cline { 2 - 5 } & $\mathrm{B} 3-2$ & 35.44 & 3.24 & 32.16 \\
\hline \multirow{2}{*}{ IV } & $\mathrm{B} 4-1$ & 32.58 & 3.06 & 31.35 \\
\cline { 2 - 5 } & $\mathrm{B} 4-2$ & 35.44 & 3.24 & 32.16 \\
\hline
\end{tabular}


Yield stress limit of reinforcement steel was estimated as $f_{y k}=550 \mathrm{MPa}$.

\subsection{Beam testing results}

Presented paper is focused on the strength of shear zones near the beam supports. Therefore, only ultimate values of forces are reported and used for comparison. The measured ultimate shear force for each beam and type of failure observed are presented in Table 2. Beams of series I and II failed due to exceeding the strength of shear zone. As observed, the inclined crack turned out to be critical one, with the inclination angle $\theta$ varying from $30^{\circ}$ to $40^{\circ}$. Series III and IV of beams lost their load carrying capacity due to premature failure in bending mode.

Table 2. Ultimate forces and type of failure modes reported for analysed beams.

\begin{tabular}{|c|c|c|c|}
\hline $\begin{array}{c}\text { Series of } \\
\text { beams }\end{array}$ & $\begin{array}{c}\text { Symbol of } \\
\text { beam }\end{array}$ & $\boldsymbol{P}_{\boldsymbol{n}}[\mathbf{k N}]$ & Type of failure \\
\hline \multirow{2}{*}{ I } & $\mathrm{B} 1-1$ & 12.5 & shear \\
\cline { 2 - 4 } & $\mathrm{B} 1-2$ & 15.0 & shear \\
\hline \multirow{2}{*}{ II } & $\mathrm{B} 2-1$ & 12.5 & shear \\
\cline { 2 - 4 } & $\mathrm{B} 2-2$ & 14.5 & shear \\
\hline \multirow{2}{*}{ III } & $\mathrm{B} 3-1$ & 21.5 & bending \\
\cline { 2 - 4 } & $\mathrm{B} 3-2$ & 21.5 & bending \\
\hline \multirow{2}{*}{ IV } & $\mathrm{B} 4-1$ & 22.0 & bending \\
\cline { 2 - 4 } & $\mathrm{B} 4-2$ & 22.0 & bending \\
\hline
\end{tabular}

The tested beams after reaching the failure load are shown in Figure 2. In Figure 2a beam B1-1 failed by exceeding the load capacity in shear zone is presented, while in Figure $2 b$ beam

B3-1 failed in bending mode is shown.

a)

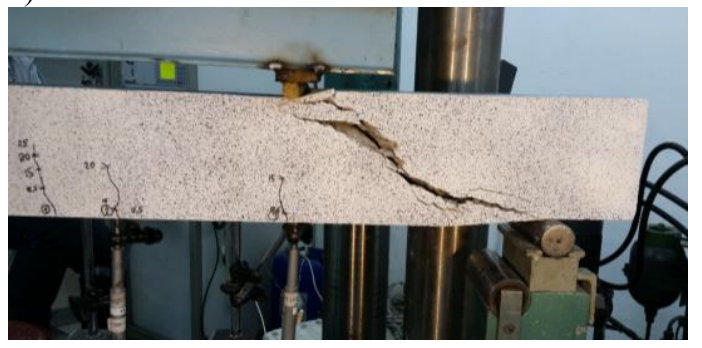

b)

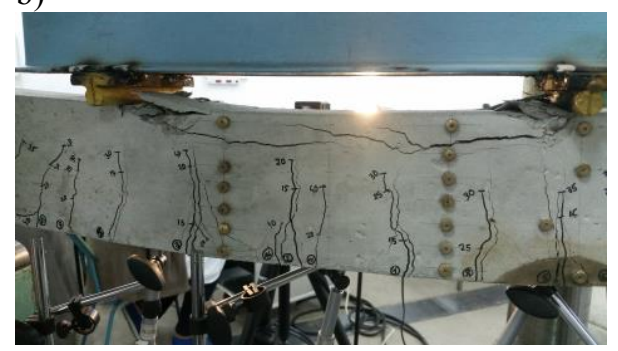

Fig. 2. Failure of RC beam: a) beam B1-1, b) beam B3-1.

\subsection{Analysis}

Having test results in form of the ultimate forces estimated in leading failure mode, i.e. due to concrete tensile capacity or transversal reinforcement strength, calculations of theoretical ultimate loads were done. These values were estimated according to three theoretical methods, described in accompanying paper [1]: classical method [2], Eurocode 2 [9] and Zararis method [4-8]. Obtained theoretical results for each series are presented in Tables $3 \div 5$. 
Table 3. Strength of concrete without shear reinforcement $V_{R d, c}[\mathrm{kN}]$.

\begin{tabular}{|c|c|c|c|c|}
\hline $\begin{array}{c}\text { Series of } \\
\text { beams }\end{array}$ & $\begin{array}{c}\text { Symbol of } \\
\text { beam }\end{array}$ & $\begin{array}{c}\text { Classica } \\
\mathbf{1} \\
\text { method }\end{array}$ & Eurocode 2 & Zararis method \\
\hline \multirow{2}{*}{ I } & B1-1 & 22.03 & 11.21 & 11.82 \\
\cline { 2 - 5 } & B1-2 & 23.26 & 11.52 & 12.08 \\
\hline \multirow{2}{*}{ II } & B2-1 & 22.03 & 11.21 & 11.82 \\
\cline { 2 - 5 } & B2-2 & 23.26 & 11.52 & 12.08 \\
\hline \multirow{2}{*}{ III } & B3-1 & 22.03 & 11.21 & 12.82 \\
\cline { 2 - 5 } & B3-2 & 23.26 & 11.52 & 11.82 \\
\hline \multirow{2}{*}{ IV } & B4-1 & 22.03 & 11.21 & 12.08 \\
\cline { 2 - 5 } & B4-2 & 23.26 & 11.52 & \\
\hline
\end{tabular}

From the analysis of strength of concrete without shear reinforcement $V_{R d, c}$ (Table 3), good compatibility between the EC2 and Zararis results can be noticed. The difference between model predictions is in the range of about $5 \%$. In that case, the shear beam capacity predicted by the classical method exceeds results of both methods by about $50 \%$. However, it has to be emphasised, that the classical method is not predestined to estimate shear strength in beams without transversal reinforcement. The design condition was taken from literature [14], where one-directional compression case was regarded with decrease factor of 0.75 .

For series no. I and II, failure occurred due to loss of shear strength, since the failure mechanism and crack pattern corresponds to theoretical analysis. Sudden growth of the inclined crack width after reaching load $P_{n}=12.5 \div 15 \mathrm{kN}$, lead to the failure. Compared to the classical method shear strength estimation, $P_{n}$ reached value at about $55 \div 65 \% V_{R d, c}$. This result indicates, that classical method overestimates the shear load capacity, which exceeds the safe values. Other methods, the EC2 and Zararis, resulted in the safe side assessment being valued at $11 \div 30 \%$ and $5 \div 24 \%$ of $V_{R d, c}$, respectively.

Table 4. Strength of beam due to crushing compressive concrete struts $V_{R d, \max }[\mathrm{kN}]$.

\begin{tabular}{|c|c|c|c|c|}
\hline $\begin{array}{c}\text { Series of } \\
\text { beams }\end{array}$ & $\begin{array}{c}\text { Symbol of } \\
\text { beam }\end{array}$ & $\begin{array}{c}\text { Classica } \\
\mathbf{1} \\
\text { method }\end{array}$ & Eurocode 2 & Zararis method \\
\hline \multirow{2}{*}{ I } & B1-1 & 260.64 & $\begin{array}{c}\text { from } 50.67 \text { for } \theta=21.8^{\circ} \\
\text { to } 73.48 \text { for } \theta=45^{\circ}\end{array}$ & N/A \\
\cline { 2 - 6 } & B1-2 & 283.20 & $\begin{array}{c}\text { from } 54.32 \text { for } \theta=21.8^{\circ} \\
\text { to } 78.76 \text { for } \theta=45^{\circ}\end{array}$ & N/A \\
\hline \multirow{2}{*}{ II } & B2-1 & 260.64 & $\begin{array}{l}\text { from } 50.67 \text { for } \theta=21.8^{\circ} \\
\text { to } 73.48 \text { for } \theta=45^{\circ}\end{array}$ & N/A \\
\cline { 2 - 6 } & B2-2 & 283.20 & $\begin{array}{l}\text { from } 54.32 \text { for } \theta=21.8^{\circ} \\
\text { to } 78.76 \text { for } \theta=45^{\circ}\end{array}$ & N/A \\
\hline \multirow{2}{*}{ III } & B3-1 & 260.64 & $\begin{array}{l}\text { from } 50.67 \text { for } \theta=21.8^{\circ} \\
\text { to } 73.48 \text { for } \theta=45^{\circ}\end{array}$ & N/A \\
\cline { 2 - 6 } & B3-2 & 283.20 & $\begin{array}{l}\text { from } 54.32 \text { for } \theta=21.8^{\circ} \\
\text { to } 78.76 \text { for } \theta=45^{\circ}\end{array}$ \\
\hline \multirow{2}{*}{ IV } & B4-1 & 260.64 & $\begin{array}{l}\text { from } 50.67 \text { for } \theta=21.8^{\circ} \\
\text { to } 73.48 \text { for } \theta=45^{\circ}\end{array}$ & N/A \\
\cline { 2 - 6 } & B4-2 & 283.20 & $\begin{array}{l}\text { from } 54.32 \text { for } \theta=21.8^{\circ} \\
\text { to } 78.76 \text { for } \theta=45^{\circ}\end{array}$ & $\mathrm{N} / \mathrm{A}$ \\
\hline
\end{tabular}


Table 5. Yielding strength of transversal reinforcement $V_{R d, s}[\mathrm{kN}]$.

\begin{tabular}{|c|c|c|c|c|}
\hline $\begin{array}{c}\text { Series of } \\
\text { beams }\end{array}$ & $\begin{array}{l}\text { Symbol of } \\
\text { beam }\end{array}$ & $\begin{array}{c}\text { Classica } \\
1 \\
\text { method }\end{array}$ & Eurocode 2 & Zararis method \\
\hline \multirow{2}{*}{ I } & $\mathrm{N} / \mathrm{A}$ & $\mathrm{N} / \mathrm{A}$ & $\mathrm{N} / \mathrm{A}$ & N/A \\
\hline & $\mathrm{N} / \mathrm{A}$ & $\mathrm{N} / \mathrm{A}$ & $\mathrm{N} / \mathrm{A}$ & $\mathrm{N} / \mathrm{A}$ \\
\hline \multirow{2}{*}{ II } & $\mathrm{N} / \mathrm{A}$ & $\mathrm{N} / \mathrm{A}$ & $\mathrm{N} / \mathrm{A}$ & $\mathrm{N} / \mathrm{A}$ \\
\hline & $\mathrm{N} / \mathrm{A}$ & $\mathrm{N} / \mathrm{A}$ & $\mathrm{N} / \mathrm{A}$ & $\mathrm{N} / \mathrm{A}$ \\
\hline \multirow{2}{*}{ III } & B3-1 & 34.56 & $\begin{array}{c}\text { from } 37.32 \text { for } \theta=45^{\circ} \\
\text { to } 93.30 \text { for } \theta=21.8^{\circ}\end{array}$ & 46.65 for $\theta=37.8^{\circ}$ \\
\hline & B3-2 & 34.56 & $\begin{array}{l}\text { from } 37.32 \text { for } \theta=45^{\circ} \\
\text { to } 93.30 \text { for } \theta=21.8^{\circ}\end{array}$ & $\begin{array}{l}46.65 \text { for } \\
\theta=37.8^{\circ}\end{array}$ \\
\hline \multirow{2}{*}{ IV } & B4-1 & 62.20 & $\begin{aligned} \text { from } 67.18 \text { for } \theta & =45^{\circ} \\
\text { to } 167.85 \text { for } \theta & =21.8^{\circ}\end{aligned}$ & $\begin{array}{l}83.97 \text { for } \\
\theta=37.8^{\circ}\end{array}$ \\
\hline & B4-2 & 62.20 & $\begin{aligned} \text { from } 67.18 \text { for } \theta & =45^{\circ} \\
\text { to } 167.85 \text { for } \theta & =21.8^{\circ}\end{aligned}$ & $\begin{array}{l}83.97 \text { for } \\
\theta=37.8^{\circ}\end{array}$ \\
\hline
\end{tabular}

In case of the third series of tests, with minimum shear reinforcement according to EC2 recommendations, good correspondence between the Zararis and EC2 shear strength estimation methods was recorded. The difference between the results is only at about $1 \div 3 \%$ range. Significantly higher shear capacity values were obtained from the classical method, according to which, the inclined crack propagates at angle of $45^{\circ}$ to horizontal axis. As it was proved, this assumption is an oversimplification which implies reduced stirrup contribution in total shear load capacity. The test results confirm theoretical predictions: based on the Aramis optical measuring system maps [14], it was noticed, that cracks are inclined at angle lower than $45^{\circ}$.

From stirrup yielding strength $V_{R d, s}$ (Table 5) for series IV, it can be noticed, that for assumed $\theta=45^{\circ}$, results of EC2 and classical method are in about $8 \%$ difference, although EC2 predicts higher values. Assessed strength according to the Zararis and EC2 approach favours EC2 by about 2\%. Values have been obtained for $\theta=37.8^{\circ}$.

The Zararis theory does not describe failure due to concrete strut crushing [1, 14], which leads to the highest differences in results comparing to other methods, thus it should be complemented to this case.

It has to be mentioned, that in case of series III and IV, bending failure mode determined the beam capacity, which in effect implies lower experimental shear capacity values than theoretical estimates.

\section{Conclusion}

Experiments focused on identification of the failure mode with preference to shear failure were carried out. Eight simply supported RC beams under four-point bending load were tested experimentally. In each beam the amount of longitudinal reinforcement was fixed, while shear reinforcement was assumed in four variants - ranging from no stirrups to overdesigned according to the EC requirements. 
Each beam was tested to the failure which resulted with different modes of failure depending on the amount of transverse reinforcement. As expected beams with reinforced below the recommended failed in the shear mode, while with the required or above the required failed in the bending mode. In case of beams failed due to shear two-branch diagonal cracks were recorded. This result confirms Zararis [4-8] finding and the proposed method of shear capacity evaluation.

Comparison of the ultimate experimentally determined load with theoretical capacity predictions was carried out. Three methods of the shear capacity assessment were used. Obtained results generally confirm experimental values when the shear mode governs the beam failure. When bending mode controls limit state the obtained results are in high discrepancy to the experiments. It was found that for beams failed in the shear mode the best predictions were delivered by Zararis or EC2 methods.

Despite decades of studies and experimental tests, no completely satisfactory analytical solution to RC beams shear strength, containing every design situation, is not available. Contemporary dimensioning methods for the shear load capacity estimations, are based on model simplifications and experimental correction factors. Even the most advanced method of Zararis is based on significant simplifications.

The most versatile EC procedure captures majority of the design cases, but is quite complicated in use. Their theoretical predictions are in good compatibility with the experimental evidence, what was also confirmed by the presented experimental results.

\section{References}

1. M. Włodarczyk, P. Czumaj, Part I - accompanying paper

2. E. Mörsch, Der Eisenbetonbau, seine Theorie und Anwendung, BDI, Verlag K. Wittwer, Stuttgart (1929)

3. F. Leonhard, R. Walther, Beton- und Stahlbetonbau (1961)

4. P. D. Zararis, Journal of Structural Engineering, 121(8), 1161-1169 (1995)

5. P. D. Zararis, Journal of Structural Engineering, 122(9), 1006-1015 (1996)

6. P. D. Zararis, Journal of Structural Engineering, 127(7), 733-742 (2001)

7. P. D. Zararis, ACI Structural Journal, 100(2), 203-214 (2003)

8. P. D. Zararis, G.Ch. Papadakis, Journal of Structural Eng. 129(4), 554-553 (2003)

9. Eurocode 2, Design of concrete structues, Part 1-1 (2004)

10. T-S., Eom, H-G. Park, ACI Structural Journal, 107(6), 689-698 (2010)

11. R.V. Rodrigues, A. Muttoni, M. F Ruiz, ACI Structural Journal 107(5), 516-525 (2010)

12. P. E. Regan, The Structural Engineer, 71,337-347 (1993)

13. L. H. Sneed, J.A. Ramirez, ACI Structural Journal, 107(5), 554-562 (2010)

14. P. Czumaj, Master's thesis ( Wrsaw University of Technology 2016) (in Polish)

15. M. Włodarczyk, P. Czumaj, TTS, 12, 135-140 (2017) (in Polish)

16. Instrukcja 194/98, (Instytut Techniki Budowlanej, Warszawa 1998) 